\title{
Rotationally-Resolved Spectroscopy of the Donor Bending Mode of $\left(\mathrm{D}_{2} \mathrm{O}\right)_{2}$
}

\author{
Jacob T. Stewart ${ }^{*}, \dagger, \S$ and Benjamin J. McCall $*, \dagger,+$ \\ ${ }^{\ddagger \dagger}$ Department of Chemistry and ${ }^{\ddagger}$ Department of Astronomy, University of Illinois, Urbana, Illinois 61801, United States
}

Supporting Information

ABSTRACT: High-resolution spectra of the intramolecular bending modes of deuterated water dimer, $\left(\mathrm{D}_{2} \mathrm{O}\right)_{2}$, have been measured using a quantum cascade laser based cavity ringdown spectrometer. Two perpendicular bands have been observed and are assigned as the $K_{a}=1 \leftarrow 0$ and $K_{a}=2 \leftarrow 1$ bands of the bending mode of the hydrogen bond donor. The tunneling splittings in the complex are well-resolved, and it is found that excitation of the donor bend has little effect on tunneling of the hydrogen bond acceptor, but causes significant perturbations on the tunneling motion which exchanges the roles of hydrogen bond donor and acceptor. The presence of this perturbation has prevented a detailed assignment of the tunneling levels in the excited state at this time. An accurate

value for the band center of the donor bend is calculated to be $1182.2 \mathrm{~cm}^{-1}$, which is in good agreement with previous theoretical calculations performed on an ab initio potential energy surface.

\section{INTRODUCTION}

Water is a ubiquitous molecule with unique properties that make it essential for life as we know it. Many of these unique properties arise because of the complex hydrogen bonding interactions that occur among water molecules. Because of the central importance of water in many fields, especially chemistry and biology, a large amount of research effort has been expended to create an accurate model of water, particularly in the liquid phase. ${ }^{1-3}$ To create an accurate model of water, it is essential to understand the detailed intermolecular interactions that occur between water molecules. To study these interactions in detail, there have been extensive experimental and theoretical studies of small, gas phase water clusters. The water dimer has been of particular interest because of the importance of two-body interactions in creating accurate models of liquid water. ${ }^{4,5}$

The water dimer has been studied by high-resolution spectroscopy throughout the microwave, ${ }^{6-13}$ submillimeter, ${ }^{13-15}$ far-IR, ${ }^{16-20}$ and mid-IR ${ }^{21,22}$ regions of the spectrum, in both isotopic forms, $\left(\mathrm{H}_{2} \mathrm{O}\right)_{2}$ and $\left(\mathrm{D}_{2} \mathrm{O}\right)_{2}$. This work has elucidated the structure of the water dimer and the details of its complex energy level structure. This complexity arises from the fact that three major tunneling motions are present in the dimer, which causes each rotational energy level to be split into six different sublevels. The high-resolution spectroscopic work has yielded energy levels and tunneling splittings of the ground state and many of the excited intermolecular vibrational states of both $\left(\mathrm{H}_{2} \mathrm{O}\right)_{2}$ and $\left(\mathrm{D}_{2} \mathrm{O}\right)_{2}$. These data have been used to develop empirical potentials for the water dimer, ${ }^{2,5,23,24}$ and

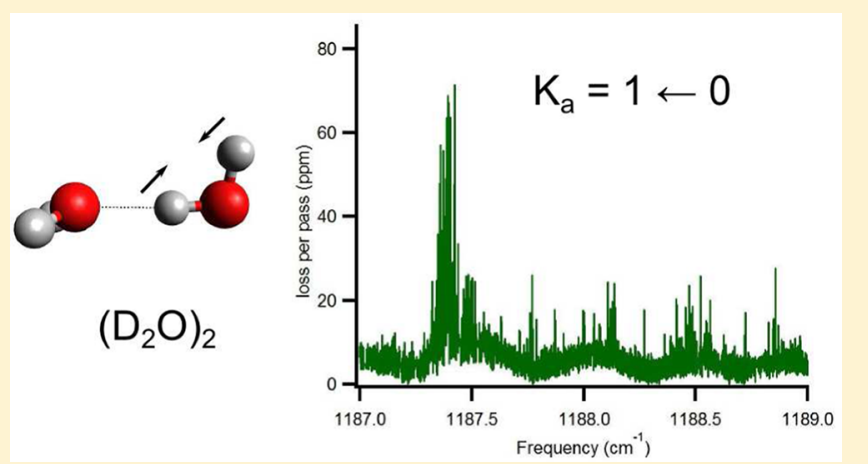

more recently ab initio potentials have been calculated and compared with the experimental data. ${ }^{25-29}$

Though the low-lying states of $\left(\mathrm{H}_{2} \mathrm{O}\right)_{2}$ and $\left(\mathrm{D}_{2} \mathrm{O}\right)_{2}$ have been comprehensively studied, much less work has been done on the intramolecular vibrational modes in the mid-IR, presumably because of the difficulty in obtaining light sources in this region that are suitable for high-resolution spectroscopy. High-resolution spectra of the intramolecular modes provide additional data to support theoretical work on the water dimer, including vibrational frequency shifts and tunneling barriers in the excited vibrational states. Recent potentials have been developed that attempt to include the effect of intramolecular vibrations, ${ }^{29}$ but only some of the intramolecular vibrations have been experimentally measured at high resolution. Huang and Miller $^{21}$ measured rotationally resolved spectra of the $\mathrm{O}-$ $\mathrm{H}$ stretching bands of $\left(\mathrm{H}_{2} \mathrm{O}\right)_{2}$, and the equivalent $\mathrm{O}-\mathrm{D}$ stretching bands of $\left(\mathrm{D}_{2} \mathrm{O}\right)_{2}$ were later measured by Paul et al. ${ }^{22}$ Low-resolution spectra of the bending modes of $\left(\mathrm{H}_{2} \mathrm{O}\right)_{2}$ have also been obtained, ${ }^{30}$ but up to this point in time, no rotationally resolved spectra of the bending modes of water dimer have been recorded.

In addition to the gas phase measurements of Paul et al., lowresolution spectra have been obtained for the bending modes of $\left(\mathrm{H}_{2} \mathrm{O}\right)_{2}$ and $\left(\mathrm{D}_{2} \mathrm{O}\right)_{2}$ in various matrices, including $\mathrm{Ar},{ }^{31,32} \mathrm{Kr},{ }^{33}$ $\mathrm{N}_{2}{ }^{34} \mathrm{Ne},{ }^{35}$ and $p-\mathrm{H}_{2} \cdot{ }^{36}$ All of these studies show that there are

Special Issue: Terry A. Miller Festschrift

Received: July 17, 2013

Revised: August 16, 2013 
two distinct frequencies in the region of the bending mode of the water dimer, which correspond to the hydrogen bond donor and acceptor subunits of the complex. All of the work on these modes agrees that the bending mode of the hydrogen bond acceptor ( $(\mathrm{A})$ in Figure 1) lies lower in frequency than the bending mode of the hydrogen bond donor $((\mathrm{B})$ in Figure 1) by $\sim 10 \mathrm{~cm}^{-1}$.

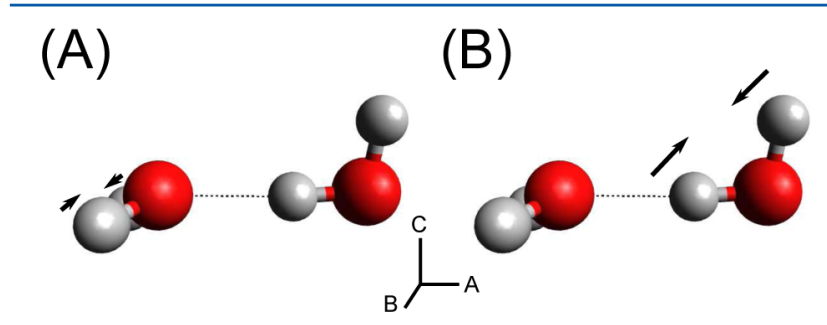

Figure 1. Representation of the two intramolecular bending modes of water dimer, corresponding to bending of (A) the hydrogen bond acceptor and (B) the hydrogen bond donor. The principal axes are also indicated in the figure.

The recent development of quantum cascade lasers (QCLs) has enabled a variety of high-resolution spectroscopic studies throughout the mid-IR. In the present work, we have utilized a QCL operating near $8.5 \mu \mathrm{m}$ to record rotationally resolved spectra of the bending mode of the hydrogen bond donor of $\left(\mathrm{D}_{2} \mathrm{O}\right)_{2}$. We have observed two perpendicular bands of this vibrational mode, which we have used to calculate the band center of the donor bend. We have also estimated the acceptor switching tunneling splittings for the $K_{a}=1$ and 2 levels in the excited state of the donor bend.

\section{EXPERIMENTAL SECTION}

High-resolution spectra of the $\left(D_{2} \mathrm{O}\right)_{2}$ bending modes were acquired using our QCL based infrared spectrometer, which has been described in detail previously. ${ }^{37,38}$ We will give a brief description of the instrument here, highlighting details pertinent to the present study. Infrared light is generated using a QCL which can be tuned from $\sim 1180-1200 \mathrm{~cm}^{-1}$ by varying the temperature and current of the laser. Light from the laser is sent to a high-finesse cavity where we perform continuous-wave (cw) cavity ringdown spectroscopy (cwCRDS) to obtain a sensitive absorption spectrum of $\mathrm{D}_{2} \mathrm{O}$ clusters that are generated in a continuous supersonic expansion. The frequency of our laser is calibrated using a combination of a mid-IR wavemeter (Bristol) and a $\mathrm{SO}_{2}$ absorption cell, using lines contained in the HITRAN database. $^{39}$ By calibrating our laser frequency with these sources, we estimate that our absolute frequency accuracy is $\sim 0.0005 \mathrm{~cm}^{-1}(15 \mathrm{MHz})$.

To generate $\left(\mathrm{D}_{2} \mathrm{O}\right)_{2}$, we bubble either argon or helium gas through a room temperature $\mathrm{D}_{2} \mathrm{O}$ (Cambridge Isotope Laboratories, $99.9 \%$ D) reservoir. The gas mixture is then sent through a $150 \mu \mathrm{m} \times 1.2 \mathrm{~cm}$ slit into a vacuum chamber that is pumped by a Roots blower and rotary vane pump (Oerlikon-Leybold). For most data presented in this paper, we used a mass flow controller (MKS Instruments) after the $\mathrm{D}_{2} \mathrm{O}$ reservoir to provide a consistent gas flow to the slit, though some spectra were obtained without the mass flow controller. Expansions were run at backing pressures of $\sim 300-400$ Torr for argon expansions and $\sim 850-950$ Torr for helium expansions, as measured by a pressure gauge attached to the input line into the vacuum chamber.

For the helium expansions, a consistent decrease in the baseline was observed over the course of scanning the laser. The decrease roughly corresponded with the amount of $\mathrm{D}_{2} \mathrm{O}$ remaining in the bubbler. A similar baseline drift was sometimes seen when the argon expansions were measured, though it was generally a smaller effect. The line width (fwhm) of individual transitions in argon expansions is $\sim 15-20 \mathrm{MHz}$; in helium expansions the lines are slightly broader, with a line width of $\sim 35-40 \mathrm{MHz}$. In both the argon and helium spectra, strong $\mathrm{D}_{2} \mathrm{O}$ and $\mathrm{HOD}$ monomer lines are present throughout the acquired data and have been removed for clarity. In the argon expansions, strong bands of $\mathrm{Ar}-\mathrm{D}_{2} \mathrm{O}$ were observed in addition to the $\mathrm{D}_{2} \mathrm{O}$-only cluster lines presented in this work. Our analysis of the $\mathrm{Ar}-\mathrm{D}_{2} \mathrm{O}$ bands has been published previously, $^{40}$ and a prior analysis of the strongest bands in this region is also available. ${ }^{41}$ The lines from these bands have also been removed from the presented data for clarity.

\section{ENERGY LEVEL STRUCTURE OF WATER DIMER}

The spectrum of the intramolecular bending modes of $\left(\mathrm{D}_{2} \mathrm{O}\right)_{2}$ is complicated by the fact that the water dimer has two distinct intramolecular bending modes, corresponding to bending of the hydrogen bond acceptor and donor subunits of the complex. These vibrations, as well as the principal axes of the complex, are shown in Figure 1. As stated above, previous experimental and theoretical studies of $\left(\mathrm{D}_{2} \mathrm{O}\right)_{2}$ have found that the donor bend ((B) in Figure 1) lies $\sim 10 \mathrm{~cm}^{-1}$ higher in energy than the acceptor bend ( $(A)$ in Figure 1$)$.

The observed spectrum is further complicated by the complex tunneling motions that occur in water dimer. There are three major tunneling motions that occur in the complex. The lowest barrier tunneling motion is an interchange of the hydrogen atoms of the acceptor subunit, which is called "acceptor switching" and causes splitting of individual rotational energy levels into two sublevels. The second tunneling motion is an interchange of the acceptor and donor subunits (referred to as "interchange tunneling") and splits each of the two sublevels from the acceptor switching into four levels, with two of the states being degenerate. The final tunneling motion is an interchange of the hydrogen atoms of the donor subunit (referred to as "bifurcation tunneling"), which causes a small shift of the degenerate $\mathrm{E}$ levels relative to the A and B levels. The overall energy level structure for an individual rotational level is shown in Figure 2 for the $K_{a}=0, J=0$ level of the ground vibrational state of $\left(\mathrm{D}_{2} \mathrm{O}\right)_{2}$. For levels with $K_{a} \geq 1$, each rotation-tunneling level is further split into two by asymmetry splitting.

A group theoretical description of water dimer was presented by Dyke $^{42}$ and gives the statistical weights and selection rules for the rotation-tunneling levels. The tunneling levels can be identified with their symmetry labels in the permutation inversion group for water dimer, which is isomorphic with the $D_{4 h}$ point group, as shown in Figure 2. The spin statistical weights for the rotational-tunneling levels of $\left(D_{2} \mathrm{O}\right)_{2}$ are $A_{1}{ }^{ \pm}$ (21), $\mathrm{B}_{1}^{ \pm}$(15), $\mathrm{A}_{2}^{ \pm}$(3), $\mathrm{B}_{2}^{ \pm}$(6), and $\mathrm{E}^{ \pm}$(18). The selection rules for transitions between these levels are $A_{1}^{+} \leftrightarrow A_{1}^{-}, B_{1}^{+} \leftrightarrow$ $\mathrm{B}_{1}^{-}, \mathrm{A}_{2}^{+} \leftrightarrow \mathrm{A}_{2}^{-}, \mathrm{B}_{2}^{+} \leftrightarrow \mathrm{B}_{2}^{-}$, and $\mathrm{E}^{+} \leftrightarrow \mathrm{E}^{-}$. 


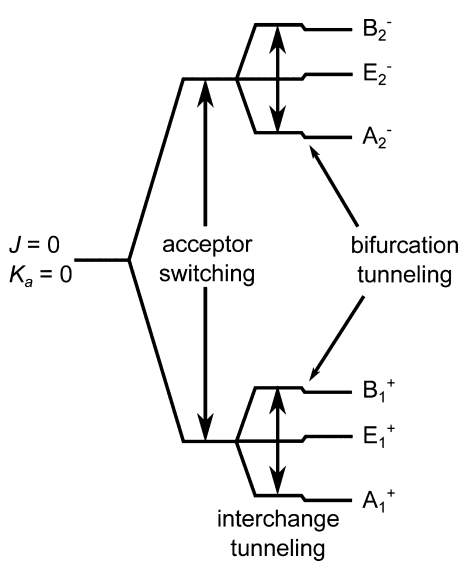

Figure 2. Energy level diagram of the tunneling sublevels of the $K_{a}=0$, $J=0$ rotational state of the ground state of $\left(\mathrm{D}_{2} \mathrm{O}\right)_{2}$. The effects of the three tunneling motions present in water dimer (acceptor switching, interchange tunneling, and bifurcation tunneling) are indicated in the figure. The symmetry labels of the resulting rotation-tunneling states are also included.

\section{RESULTS}

The supersonic expansion that we use to produce $\left(\mathrm{D}_{2} \mathrm{O}\right)_{2}$ also produces a variety of other species, such as larger water clusters and clusters containing $\mathrm{D}_{2} \mathrm{O}$ in combination with the carrier gas. To determine which absorption features arise from wateronly clusters (i.e., $\left.\left(\mathrm{D}_{2} \mathrm{O}\right)_{n}\right)$, we used both $\mathrm{Ar}$ and $\mathrm{He}$ as the carrier gas for the expansion. The absorption features we report here were present in expansions with both carrier gases, confirming that they are due to $\left(\mathrm{D}_{2} \mathrm{O}\right)_{n}$ clusters. After finding the lines from water-only clusters, we have followed the approach of Cruzan et al. ${ }^{43}$ to determine the number of $\mathrm{D}_{2} \mathrm{O}$ units in the cluster. This is done by recording absorption spectra of the expansion using several different mixtures of $\mathrm{D}_{2} \mathrm{O}$ and $\mathrm{H}_{2} \mathrm{O}$. We assume that the $\mathrm{H}$ and $\mathrm{D}$ atoms in the liquid mixture rapidly equilibrate to produce a statistical mixture of $\mathrm{D}_{2} \mathrm{O}, \mathrm{H}_{2} \mathrm{O}$, and HOD. If we neglect any kinetic isotope effects for this rearrangement, the following relationship can be used to determine the cluster size:

$$
\ln \left(\frac{I}{I_{0}}\right)=2 n \ln \left(\chi_{\mathrm{D}_{2} \mathrm{O}}\right)
$$

In this equation, $I$ is the intensity of an absorption feature for an expansion using a $\mathrm{D}_{2} \mathrm{O} / \mathrm{H}_{2} \mathrm{O}$ mixture, $I_{0}$ is the intensity of the feature for an expansion of pure $\mathrm{D}_{2} \mathrm{O}, n$ is the cluster size (i.e., $n$ $=2$ for water dimer), and $\chi_{\mathrm{D}_{2} \mathrm{O}}$ is the mole fraction of $\mathrm{D}_{2} \mathrm{O}$ in the mixture. By recording absorption spectra with a range of values for $\chi_{\mathrm{D}_{2} \mathrm{O}}$, we can plot $\ln \left(I / I_{0}\right)$ versus $\ln \left(\chi_{\mathrm{D}_{2} \mathrm{O}}\right)$ to find the slope of the line, which gives the cluster size. Figure 3 shows such a plot for absorption features we recorded near 1195.55 $\mathrm{cm}^{-1}$, which belong to the Q-branch of the $K_{a}=2 \leftarrow 1$ subband of the donor bending mode. The slope of the line in Figure 3 is $3.93 \pm 0.33$, which agrees with the expected value of 4 for $\left(\mathrm{D}_{2} \mathrm{O}\right)_{2}$.

We have observed two main bands of $\left(\mathrm{D}_{2} \mathrm{O}\right)_{2}$ near 1187 and $1195 \mathrm{~cm}^{-1}$, which we assign as the $K_{a}=1 \leftarrow 0$ and $K_{a}=2 \leftarrow 1$ sub-bands of the bending mode of the hydrogen bond donor. We assign these bands to the donor bend because, as noted above, previous experimental and theoretical work has shown that the donor bend lies $\sim 10 \mathrm{~cm}^{-1}$ higher in frequency than the acceptor bend. We have obtained spectra of Ar expansions up

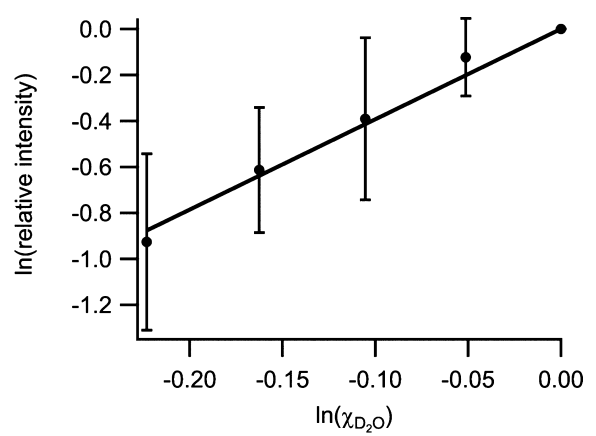

Figure 3. Plot of $\ln \left(\right.$ relative intensity) versus $\ln \left(x_{\mathrm{D}_{2} \mathrm{O}}\right)$ for several $\mathrm{D}_{2} \mathrm{O} / \mathrm{H}_{2} \mathrm{O}$ mixtures to determine the cluster size responsible for absorption features recorded near $1195.55 \mathrm{~cm}^{-1}$. Multiple measurements of the absorption intensity were made for pure $\mathrm{D}_{2} \mathrm{O}$ and mixtures of $95 \%, 90 \%, 85 \%$, and $80 \% \mathrm{D}_{2} \mathrm{O}$ diluted with $\mathrm{H}_{2} \mathrm{O}$. The intercept of the linear fit was fixed to 0 , and the resulting slope is 3.93 \pm 0.33 , indicating a cluster size of 2 . The error bars and uncertainty indicate a $95 \%$ confidence level.

to $\sim 1204 \mathrm{~cm}^{-1}$ and have not seen any strong absorption features beyond $1200 \mathrm{~cm}^{-1}$. There are some weak absorption features near $1203 \mathrm{~cm}^{-1}$, but these are most likely from the $K_{a}$ $=3 \leftarrow 2$ sub-band. In contrast, spectra of both $\mathrm{Ar}$ and $\mathrm{He}$ expansions recorded down to $\sim 1182 \mathrm{~cm}^{-1}$ show strong absorption features throughout the frequency region to the red of these two main bands in both carrier gases. Although we have not yet been able to definitively assign these absorption features, they may due to the acceptor bend, meaning the higher frequency features we present here must arise from the donor bend.

On the basis of the energy level structure of $\left(\mathrm{D}_{2} \mathrm{O}\right)_{2}$ outlined in the previous section, we expect that there will be six separate tunneling sub-bands for each of the $K_{a}=1 \leftarrow 0$ and $K_{a}=2 \leftarrow 1$ sub-bands of $\left(D_{2} \mathrm{O}\right)_{2}$. These six bands will be split into two groups of three by the acceptor switching tunneling motion of the complex, resulting in two main groups of tunneling levels. These two groups are the tunneling levels with $\mathrm{A}_{1}^{+}, \mathrm{E}_{1}^{+}$, and $\mathrm{B}_{1}^{+}$ symmetry (the lower three levels in Figure 2) and the levels with $\mathrm{A}_{2}^{-}, \mathrm{E}_{2}^{-}$, and $\mathrm{B}_{2}^{-}$symmetry (the upper three levels in Figure 2 ). The acceptor switching tunneling splitting has not been directly measured, but it has been estimated to range from $\sim 1.2$ to $1.8 \mathrm{~cm}^{-1}$ from microwave ${ }^{12}$ and infrared ${ }^{22}$ studies of $\left(\mathrm{D}_{2} \mathrm{O}\right)_{2}$. The magnitude of this splitting will lead to a clear separation of the two groups of tunneling levels in the spectrum. The three levels in each group will then be separated by the interchange tunneling splitting, which has been directly measured to be $1172 \mathrm{MHz}\left(0.039 \mathrm{~cm}^{-1}\right)$ for the splitting between the $A_{1}^{+}$and $\mathrm{B}_{1}^{+}$levels, and $1083 \mathrm{MHz}\left(0.036 \mathrm{~cm}^{-1}\right)$ for the splitting between the $\mathrm{A}_{2}^{-}$and $\mathrm{B}_{2}^{-}$levels in the ground state for $K_{a}=0 .{ }^{11}$ Because the interchange tunneling splitting is only $\sim 0.04 \mathrm{~cm}^{-1}$, the three sub-bands corresponding to the tunneling levels are closely spaced, leading to substantial overlap of the Q-branches of the tunneling sub-bands. For the $K_{a}=2 \leftarrow 1$ sub-band, the spectrum is further complicated by asymmetry splitting in the $K_{a}=1$ level in the ground state. ${ }^{1}$

Our observed spectra for the $K_{a}=1 \leftarrow 0$ band in an Ar expansion are presented in Figure 4. Our frequency coverage of this region with a He expansion is limited to the Q-branch region and the $\mathrm{R}(0)$ lines because there was a gap in the frequency coverage of our QCL when the He spectra were recorded. Spectra of both $\mathrm{Ar}$ and He expansions are available 


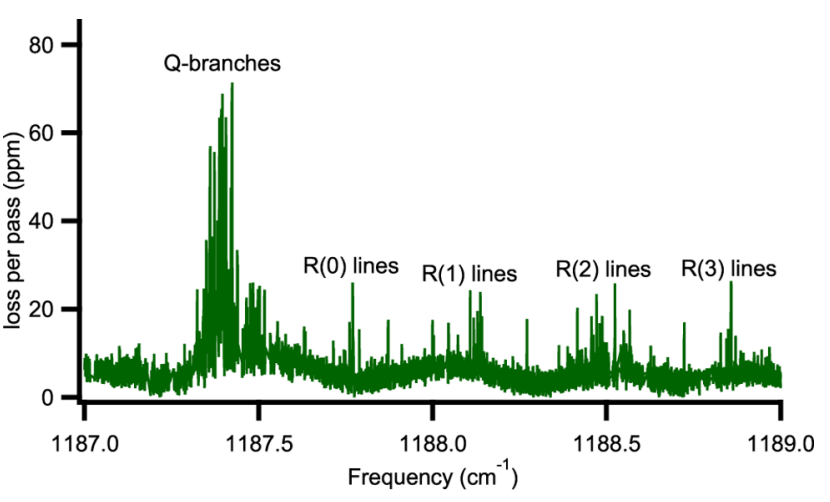

Figure 4. Observed spectrum of the $K_{a}=1 \leftarrow 0$ sub-band of the bending mode of the hydrogen bond donor measured in an $\mathrm{Ar}$ supersonic expansion. The relative strength of these features identifies them as arising from the $A_{1}^{+} / E_{1}^{+} / B_{1}^{+}$tunneling levels. The densely packed region of $\mathrm{Q}$-branches and the $\mathrm{R}$-branch lines are labeled in the figure. Because not all spectra were acquired with the same background level due to changes in alignment of the ringdown cavity over time, the spectra were brought to the same level by subtracting the minimum point in a scan from the entire scan. The apparent gap in the Q-branches is due to a strong absorption from $\mathrm{D}_{2} \mathrm{O}$ monomer, which has been removed from the spectrum for clarity.

further to the red from what is shown in Figure 4. As can be seen in the figure, there is a dense cluster of absorption lines near $1187.4 \mathrm{~cm}^{-1}$, which arises from the series of overlapping Q-branches from multiple tunneling states. Because these Qbranches are much stronger than anything else nearby in the spectrum, we attribute them to the $A_{1}^{+} / E_{1}^{+} / B_{1}^{+}$tunneling levels, because these levels carry a larger statistical weight than the $A_{2}^{-} /$ $\mathrm{E}_{2}^{-} / \mathrm{B}_{2}^{-}$tunneling levels. Clusters of R-branch transitions are also observed and labeled in the figure, which are spaced at $\sim 0.36 \mathrm{~cm}^{-1}$. The $0.36 \mathrm{~cm}^{-1}$ spacing is approximately equal to 2 times the known $B$ rotational constant for $\left(D_{2} \mathrm{O}\right)_{2}(B=0.1812$ $\mathrm{cm}^{-1}$ in the ground state), supporting the assignment of these absorption lines to $\left(\mathrm{D}_{2} \mathrm{O}\right)_{2}$. $\mathrm{R}(0)$ transitions are observed, which aids in identifying the sub-band as $K_{a}=1 \leftarrow 0$. Only a few possible P-branch transitions were observed, presumably because they were too weak due to the reduction in P-branch intensities for $\Delta K_{a}=+1$ bands. ${ }^{44}$ A similar effect was observed in measurements of the hydrogen bond acceptor antisymmetric stretch of $\left(\mathrm{D}_{2} \mathrm{O}\right)_{2}{ }^{22}$

The $K_{a}=2 \leftarrow 1$ band of $\left(\mathrm{D}_{2} \mathrm{O}\right)_{2}$ lies near $1195.5 \mathrm{~cm}^{-1}$ and is shown in Figure 5 for an $\mathrm{Ar}$ expansion. The same features have also been observed using a He expansion. As can be seen in the figure, there is again a densely packed region caused by overlapping Q-branches of multiple tunneling components, with groups of R-branch lines spaced at $\sim 0.36 \mathrm{~cm}^{-1}$. Because of the strength of the band, we attribute this band to the $A_{1}^{+} / E_{1}^{+}$/ $\mathrm{B}_{1}^{+}$tunneling levels. For this band, no $\mathrm{R}(0)$ transitions are observed, indicating that this band is $K_{a}=2 \leftarrow 1$. Again, the Pbranch transitions are expected to be weaker in this $\Delta K_{a}=+1$ band and are not observed in either Ar or He expansions.

The identification of these two bands as $K_{a}=1 \leftarrow 0$ and $K_{a}=$ $2 \leftarrow 1$ bands is further confirmed by their frequency separation. For a near-prolate top such as $\left(\mathrm{D}_{2} \mathrm{O}\right)_{2}$, the Q-branches of adjacent sub-bands will be separated by $\sim 2\left(\mathrm{~A}^{\prime}-\mathrm{B}^{\prime}\right) .{ }^{44}$ Though $\mathrm{A}^{\prime}$ and $\mathrm{B}^{\prime}$ are unknown for this band, we can assume that they will be close to their ground state values. Using the ground state values $^{45}$ of $4.17 \mathrm{~cm}^{-1}$ for $\mathrm{A}$ and $0.181 \mathrm{~cm}^{-1}$ for $\mathrm{B}$, the expected separation between the $\mathrm{Q}-$ branches should be $\sim 8 \mathrm{~cm}^{-1}$. If we take the center of the $\mathrm{Q}$-branch regions as a rough

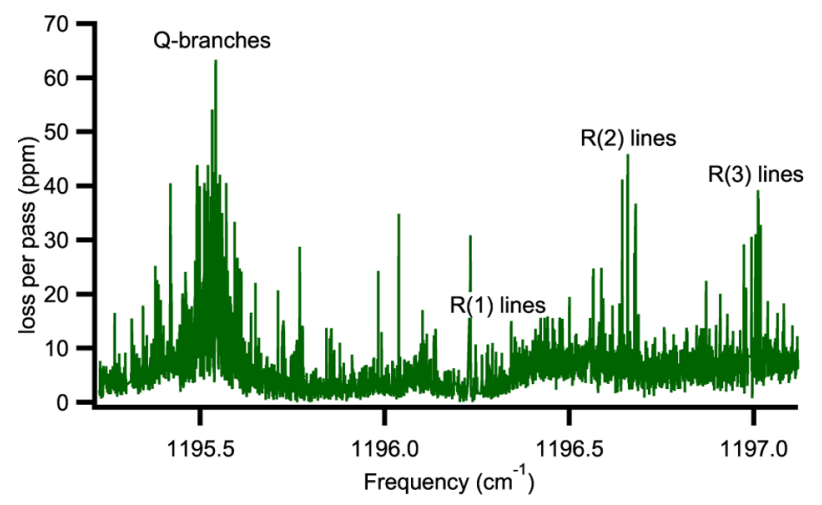

Figure 5. Observed spectrum of the $K_{a}=2 \leftarrow 1$ sub-band of the bending mode of the hydrogen bond donor measured in an $\mathrm{Ar}$ supersonic expansion. The relative strength of these features identifies them as arising from the $A_{1}^{+} / E_{1}^{+} / B_{1}^{+}$tunneling levels. The densely packed region of Q-branches and the R-branch lines are labeled in the figure. Because not all spectra were acquired with the same background level due to changes in alignment of the ringdown cavity over time, the spectra were brought to the same level by subtracting the minimum point in a scan from the entire scan.

approximation of the band center for the sub-bands we have observed, we estimate a separation of $\sim 8.1 \mathrm{~cm}^{-1}$, which agrees well with the expected separation on the basis of the ground state constants.

We have attempted to assign the spectra using a near-prolate top energy level expression, as has been done previously for water dimer but were unable to obtain an unambiguous assignment. The many overlapping peaks in the Q-branch regions have made it difficult to use Q-branch transitions in making assignments, so our attempts have focused on the Rbranch transitions (and the P-branch transitions we observed for the $K_{a}=1 \leftarrow 0$ band). Though the groups of peaks appear at a regular $0.36 \mathrm{~cm}^{-1}$ interval, there does not appear to be the expected triplet pattern for the $\mathrm{A}_{1}^{+} / \mathrm{E}_{1}^{+} / \mathrm{B}_{1}^{+}$tunneling levels. This is illustrated in Figure 6, which shows close-up views of the Rbranch lines we have observed for the $K_{a}=1 \leftarrow 0$ band. A list of the frequencies of the observed transitions is provided in Table S1 in the Supporting Information. Only the $\mathrm{R}(0)$ lines show a possible triplet pattern that is seen in both $\mathrm{Ar}$ and $\mathrm{He}$ expansions. For the transitions with $J^{\prime \prime}>1$, more than three lines are observed, which is unexpected for the $K_{a}=1 \leftarrow 0$ band, as there should not be any asymmetry doubling, as in the $K_{a}=2 \leftarrow 1$ band. Unfortunately, we were not able to obtain data using a $\mathrm{He}$ expansion in this frequency region, so it is possible some of the extra lines could be attributed to some form of $\mathrm{Ar}-\mathrm{D}_{2} \mathrm{O}$ cluster.

For the $K_{a}=2 \leftarrow 1$ band, we have data for both $\mathrm{Ar}$ and $\mathrm{He}$ expansions, which are shown in Figures 7 and 8, respectively. A list of the frequencies of the observed transitions is provided in Table S2 in the Supporting Information. For this sub-band, we again expect a triplet pattern for the three tunneling levels, but each of the components of the triplet will be composed of two lines separated by asymmetry splitting, which should be the same for all tunneling levels. ${ }^{14}$ The groups of lines in Figures 7 and 8 do not show this pattern, which again has made it difficult to obtain a detailed assignment and fit of the interchange tunneling levels. It is unclear what is causing the irregular patterns in the R-branch lines for both the $K_{a}=1 \leftarrow 0$ and $K_{a}=$ $2 \leftarrow 1$ bands we have observed, though it must arise from the excitation of the bending vibration in the donor subunit. A 

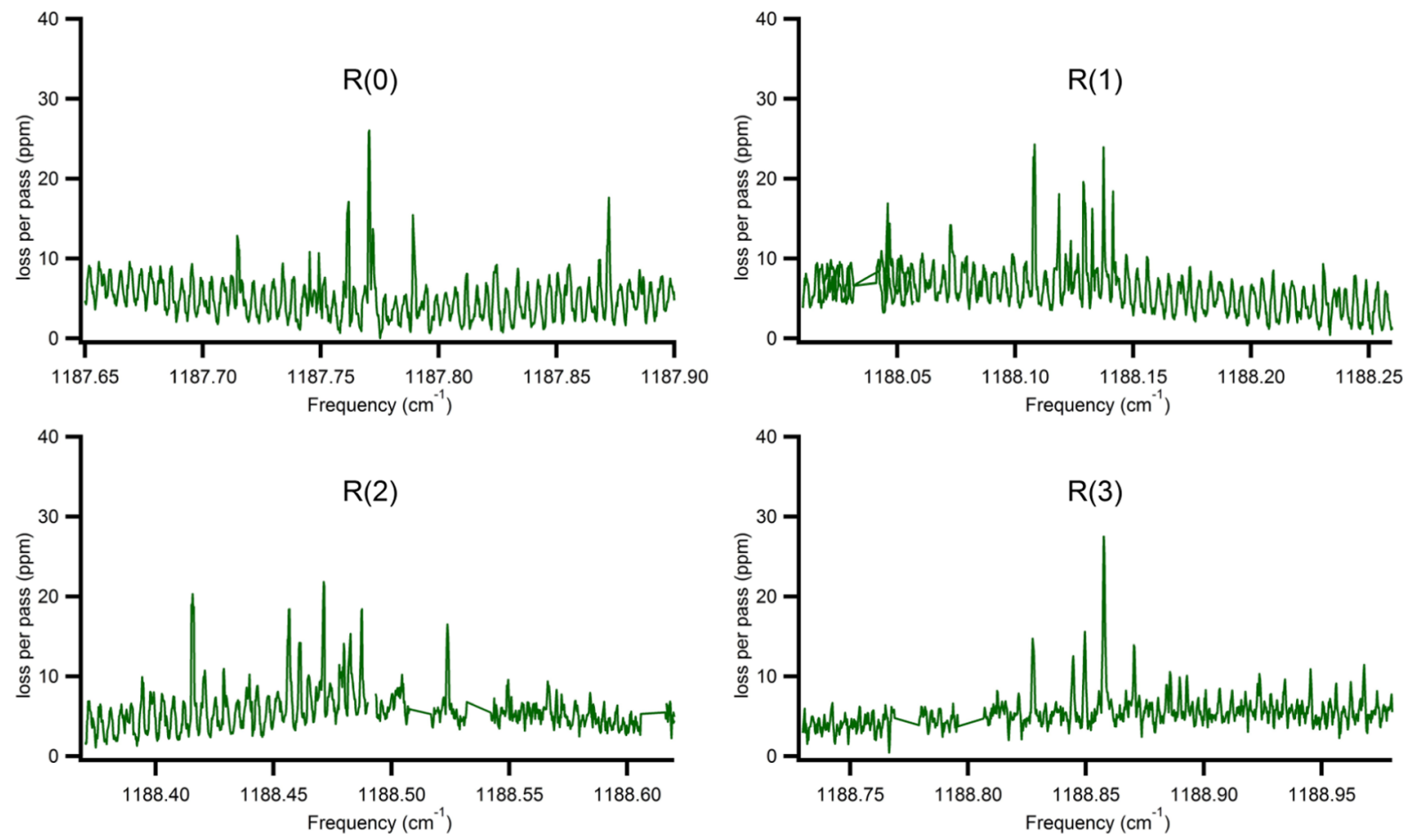

Figure 6. Zoomed-in views of the groups of R-branch lines of the $K_{a}=1 \leftarrow 0$ band measured in an Ar expansion. Each panel is offset $0.36 \mathrm{~cm}^{-1}$ from the previous panel, and all panels are $0.25 \mathrm{~cm}^{-1}$ wide. The gaps that are present are due to removal of monomer transitions.
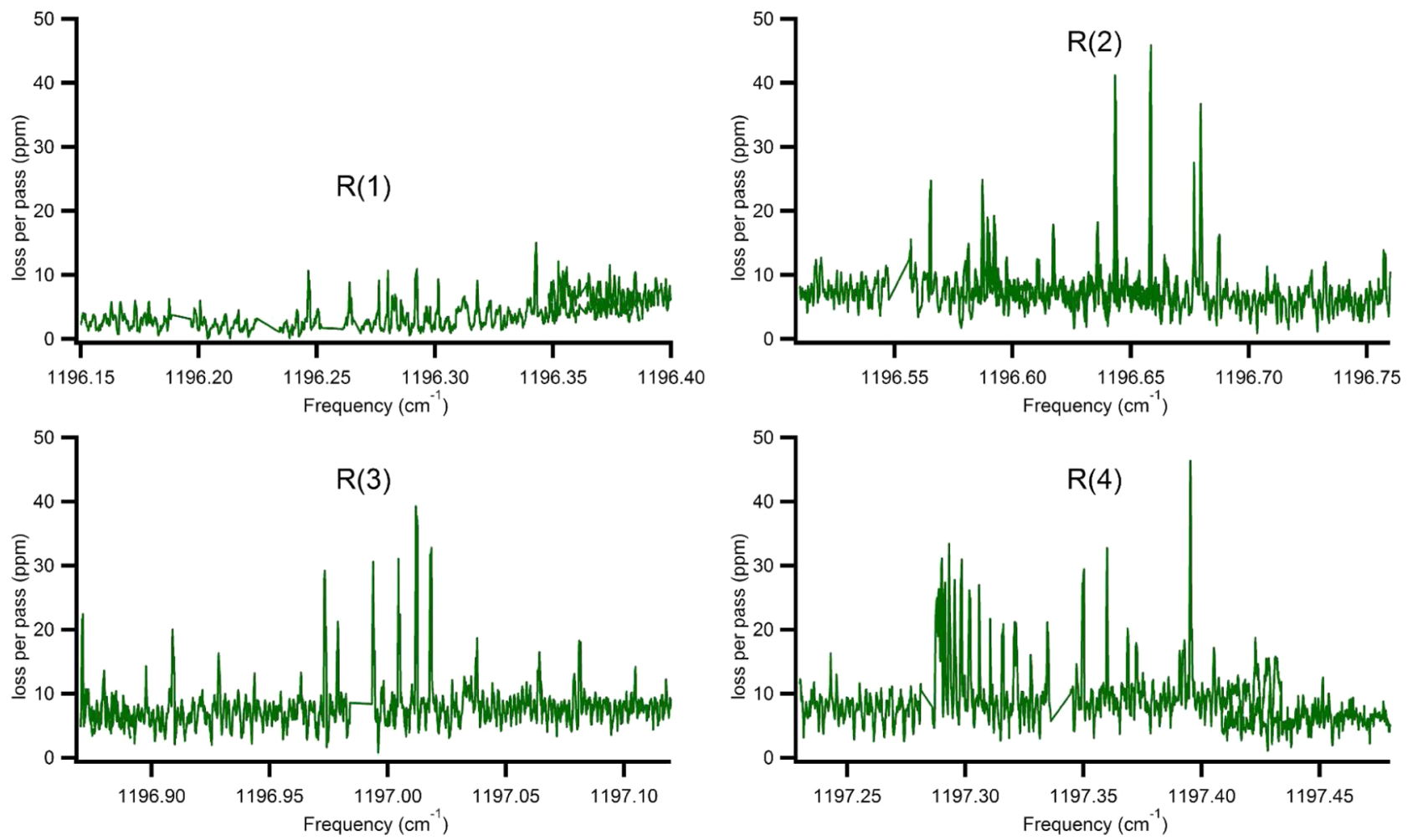

Figure 7. Zoomed-in views of the groups of R-branch lines of the $K_{a}=2 \leftarrow 1$ band measured in an Ar expansion. Each panel is offset $0.36 \mathrm{~cm}^{-1}$ from the previous panel, and all panels are $0.25 \mathrm{~cm}^{-1}$ wide. The gaps that are present are due to removal of monomer and $\mathrm{Ar}-\mathrm{D}_{2} \mathrm{O}$ transitions. The group of lines near $1197.28 \mathrm{~cm}^{-1}$ are likely due to an unassigned band of $\mathrm{Ar}-\mathrm{D}_{2} \mathrm{O}$.

previous study ${ }^{21}$ of the $\left(\mathrm{H}_{2} \mathrm{O}\right)_{2}$ stretching modes observed a large decrease in the frequency of the interchange tunneling when the acceptor antisymmetric stretch was excited, which was attributed to a breakdown in the Born-Oppenheimer approximation separating the high-frequency and low-frequency vibrations. ${ }^{46} \mathrm{~A}$ similar situation is occurring in the present case, as the vibrational excitation must be transferred between the two $\mathrm{D}_{2} \mathrm{O}$ subunits for interchange tunneling to 

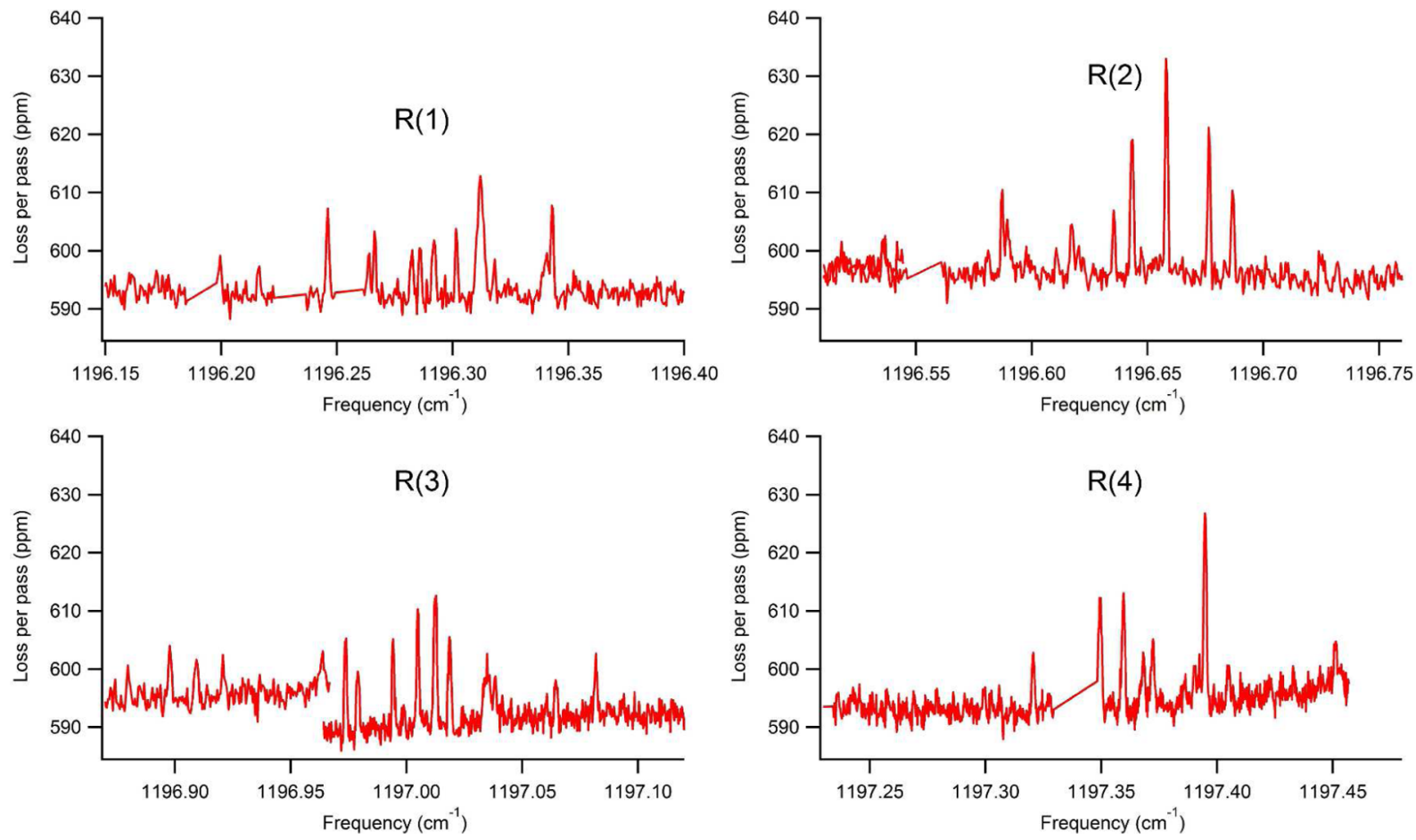

Figure 8. Zoomed-in views of the groups of R-branch lines of the $K_{a}=2 \leftarrow 1$ band measured in a He expansion. Each panel is offset $0.36 \mathrm{~cm}^{-1}$ from the previous panel, and all panels are $0.25 \mathrm{~cm}^{-1}$ wide. The gaps that are present are due to removal of monomer transitions.

occur, which means that there is likely coupling between the high-frequency bend and low-frequency tunneling. It should also be noted that the motion of the donor bend lies along the pathway of the bifurcation tunneling, meaning that coupling between the donor bend and the bifurcation tunneling is likely occurring as well.

In addition to the strong bands reported above, we have also seen features that we assign as bands arising from the $\mathrm{A}_{2}^{-}, \mathrm{E}_{2}^{-}$, and $\mathrm{B}_{2}^{-}$tunneling levels for both the $K_{a}=1 \leftarrow 0$ and $K_{a}=2 \leftarrow$ 1 bands. Because the statistical weights of these levels are much lower than the $A_{1}^{+} / E_{1}^{+} / B_{1}^{+}$levels (with the exception of the $E_{2}^{-}$ level) the absorption bands are much weaker. We have only been able to observe the Q-branches of these levels, which are shown in Figures 9 and 10 for the $K_{a}=1 \leftarrow 0$ and $K_{a}=2 \leftarrow 1$ bands, respectively, alongside the stronger Q-branches of the $\mathrm{A}_{1}^{+} / \mathrm{E}_{1}^{+} / \mathrm{B}_{1}^{+}$levels. Though the figures show only the spectra from Ar expansions, the features are also observed in $\mathrm{He}$

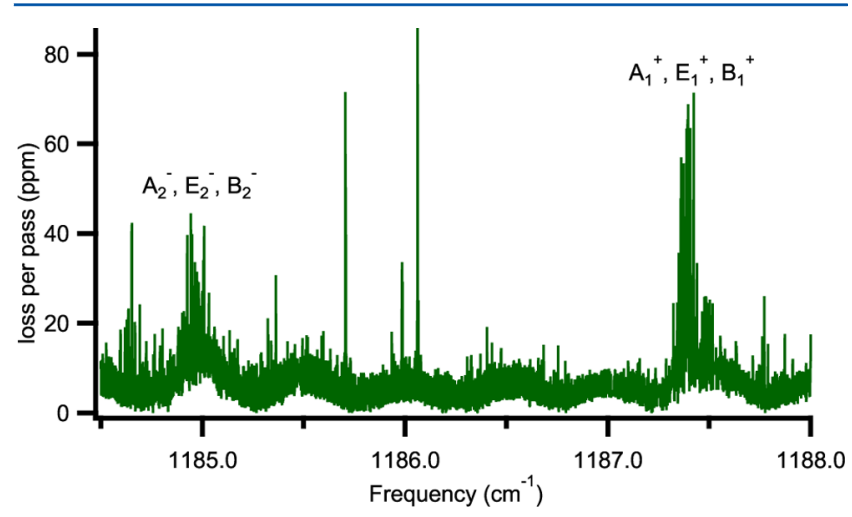

Figure 9. Q-branches of the $K_{a}=1 \leftarrow 0$ band for both the $A_{1}^{+} / \mathrm{E}_{1}^{+} / \mathrm{B}_{1}^{+}$ tunneling levels and the $A_{2}^{-} / E_{2}^{-} / B_{2}^{-}$tunneling levels as observed in an Ar expansion. The two sets of levels are separated by $\sim 2.4 \mathrm{~cm}^{-1}$.

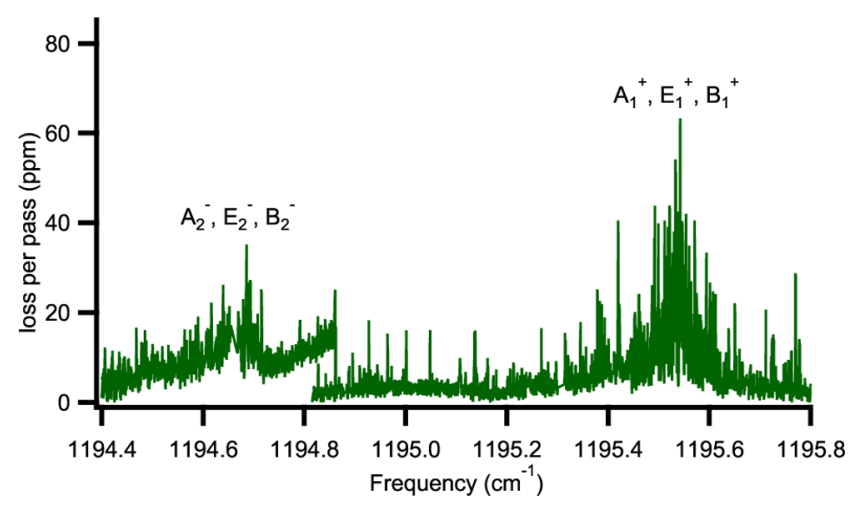

Figure 10. Q-branches of the $K_{a}=2 \leftarrow 1$ band for both the $\mathrm{A}_{1}^{+} / \mathrm{E}_{1}^{+} / \mathrm{B}_{1}^{+}$ tunneling levels and the $\mathrm{A}_{2}^{-} / \mathrm{E}_{2}^{-} / \mathrm{B}_{2}^{-}$tunneling levels as observed in an Ar expansion. The two sets of levels are separated by $\sim 0.9 \mathrm{~cm}^{-1}$.

expansions. Because the bands are much weaker, we have not been able to identify R-branch transitions associated with the observed Q-branches. For the $K_{a}=1 \leftarrow 0$ band, the separation between these Q-branches is $\sim 2.4 \mathrm{~cm}^{-1}$, and for the $K_{a}=2 \leftarrow 1$ band, the separation is $\sim 0.9 \mathrm{~cm}^{-1}$. A summary of the frequency positions of the bands we have reported is presented in Table 1.

\section{DISCUSSION}

From the spectra and assignments presented above, we can calculate the gas-phase frequency of the donor bend and compare it to previous experiments and theoretical predictions. As noted above, the spacing between Q-branches of adjacent sub-bands of a near-prolate top are separated by $\sim 2\left(\mathrm{~A}^{\prime}-\mathrm{B}^{\prime}\right)$, which is $\sim 8 \mathrm{~cm}^{-1}$ for $\left(\mathrm{D}_{2} \mathrm{O}\right)_{2}$. The band center for the vibrational band lies midway between the $K_{a}=1 \leftarrow 0$ and $K_{a}=$ $0 \leftarrow 1$ sub-bands, so the band center is $\sim 4 \mathrm{~cm}^{-1}$ to the red of the $K_{a}=1 \leftarrow 0$ band. To attempt to estimate the band center without the influence of the acceptor switching tunneling, we 
Table 1. Approximate Center Frequency Positions of the $K_{a}$ $=1 \leftarrow 0$ and $K_{a}=2 \leftarrow 1$ Sub-bands of the Donor Bend of $\left(\mathrm{D}_{2} \mathrm{O}\right)_{2}{ }^{a}$

$\begin{array}{lc}\text { band } & \text { frequency }\left(\mathrm{cm}^{-1}\right) \\ K_{a}=1 \leftarrow 0\left(\mathrm{~A}_{1}^{+} / \mathrm{E}_{1}^{+} / \mathrm{B}_{1}^{+} \text {levels }\right) & 1187.39 \\ K_{a}=1 \leftarrow 0\left(\mathrm{~A}_{2}^{-} / \mathrm{E}_{2}^{-} / \mathrm{B}_{2}^{-} \text {levels }\right) & 1184.97 \\ K_{a}=2 \leftarrow 1\left(\mathrm{~A}_{1}^{+} / \mathrm{E}_{1}^{+} / \mathrm{B}_{1}^{+} \text {levels }\right) & 1195.54 \\ K_{a}=2 \leftarrow 1\left(\mathrm{~A}_{2}^{-} / \mathrm{E}_{2}^{-} / \mathrm{B}_{2}^{-} \text {levels }\right) & 1194.68\end{array}$

${ }^{a_{T}}$ The frequency positions listed are approximate values based on the center of the cluster of Q-branches observed for each band.

can average the positions of the $A_{1}^{+} / E_{1}^{+} / B_{1}^{+}$and $A_{2}^{-} / E_{2}^{-} / B_{2}^{-}$ tunneling components of the $K_{a}=1 \leftarrow 0$ band before calculating the band center. Doing so gives an estimated band center of $1182.2 \mathrm{~cm}^{-1}$. This value is compared to previous experiments and calculations in Table 2. As shown in the table,

Table 2. Comparison of the Frequency of the Donor Bending Mode of $\left(\mathrm{D}_{2} \mathrm{O}\right)_{2}$ in the Present Study to Previous Experimental and Theoretical Work

\begin{tabular}{lc}
\multicolumn{1}{c}{ method } & frequency $\left(\mathrm{cm}^{-1}\right)$ \\
gas phase (present work) & 1182.2 \\
$\mathrm{Ne}$ matrix $^{35}$ & 1192.2 \\
Ar matrix & \\
$\mathrm{Kr}^{31}$ matrix $^{33}$ & 1189.1 \\
$\mathrm{~N}_{2}$ matrix $^{34}$ & 1187.0 \\
- $_{2}$ matrix $^{36}$ & 1192.7 \\
DFT $^{36}$ & 1190 \\
MULTIMODE $^{26}$ & 1176
\end{tabular}

the MULTIMODE calculations of Wang et al. ${ }^{26}$ on an ab initio potential energy surface ${ }^{25}$ produce a value in very good agreement with the gas phase spectra recorded here. Previous studies in various matrices consistently measured values that are higher in frequency than the gas phase value reported here. This is the opposite effect of what is seen with the $\left(D_{2} \mathrm{O}\right)_{2}$ stretching modes, where the matrix values are consistently lower in frequency than the gas phase values measured by cavity ringdown spectroscopy. ${ }^{26}$ The magnitude of the matrix shift is also greater by about a factor of 2 for the stretches as compared to the bending modes considered here. The difference between the gas phase and matrix data is likely due to a combination of perturbations from the matrix on $\left(D_{2} \mathrm{O}\right)_{2}$ and the lack of rotational resolution making it difficult to assign the true band center. The DFT calculations performed by Ceponkus et al. ${ }^{36}$ in connection with their $p-\mathrm{H}_{2}$ matrix work produced a value significantly lower in frequency than the gas phase value we report.

It is interesting to note that the band center for the donor bending mode lies just below the recently measured dissociation energy $\left(D_{0}\right)$ of $\left(D_{2} \mathrm{O}\right)_{2}$ reported by Ch'ng et al. ${ }^{47}$ Ch'ng et al. used velocity map imaging to determine $D_{0}$ to be $1244 \pm 10 \mathrm{~cm}^{-1}$, which is in excellent agreement with theoretical calculations by Czakó et al., who determined $D_{0}$ to be $1244 \pm 5 \mathrm{~cm}^{-1}$. ${ }^{48}$ The fact that the bending modes of $\left(D_{2} \mathrm{O}\right)_{2}$ lie below $D_{0}$ explains why the rotational-tunneling levels are well-resolved in the present experiment, instead of being broadened, as appears to be the case for the bending modes of $\left(\mathrm{H}_{2} \mathrm{O}\right)_{2} \cdot{ }^{30}$ Because the band center of the donor bending mode only lies $\sim 60 \mathrm{~cm}^{-1}$ below the dissociation energy, it may be possible to measure a more precise dissociation energy by observing combination bands of the bending modes of $\left(\mathrm{D}_{2} \mathrm{O}\right)_{2}$ with low-lying intramolecular vibrations.

The separation between the $A_{1}^{+} / E_{1}^{+} / B_{1}^{+}$and $A_{2}^{-} / E_{2}^{-} / B_{2}^{-}$ tunneling levels provides information regarding the acceptor switching tunneling splitting in the excited state of the donor bend. Because the donor bend is symmetric under the $C_{s}$ point group of $\left(D_{2} \mathrm{O}\right)_{2}$, the ordering of the $A_{1}^{+} / E_{1}^{+} / B_{1}^{+}$and $A_{2}^{-} / E_{2}^{-} / B_{2}^{-}$ tunneling levels is expected to stay the same in the vibrationally excited state, ${ }^{42}$ instead of being reversed, as in the case of the acceptor antisymmetric stretch. ${ }^{21,22}$ The energy levels are depicted in Figure 11, with arrows indicating the bands

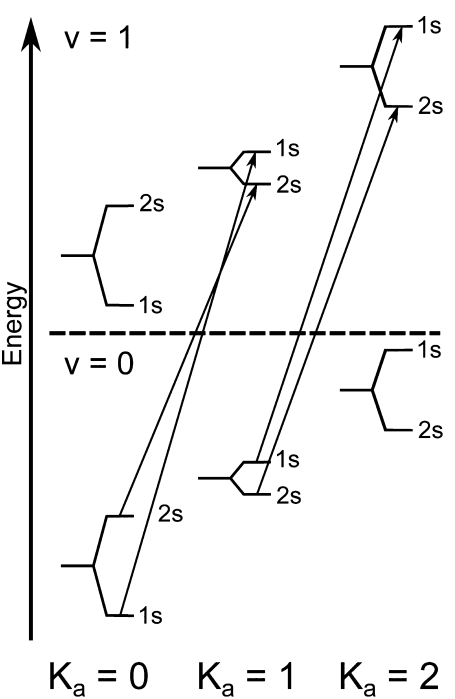

Figure 11. Energy level diagram for the observed $\left(\mathrm{D}_{2} \mathrm{O}\right)_{2}$ bands. The $1 \mathrm{~s}$ in the figure refer to the $\mathrm{A}_{1}^{+} / \mathrm{E}_{1}^{+} / \mathrm{B}_{1}^{+}$tunneling levels, and the $2 \mathrm{~s}$ refer to the $\mathrm{A}_{2}^{-} / \mathrm{E}_{2}^{-} / \mathrm{B}_{2}^{-}$tunneling levels. The bands observed in this work are indicated by arrows.

observed in the current study. As can be seen in the figure, the $2.4 \mathrm{~cm}^{-1}$ separation between the $\mathrm{A}_{1}^{+} / \mathrm{E}_{1}^{+} / \mathrm{B}_{1}^{+}$and $\mathrm{A}_{2}^{-} / \mathrm{E}_{2}^{-} / \mathrm{B}_{2}^{-}$ tunneling levels in the $K_{a}=1 \leftarrow 0$ band provides the sum of the acceptor switching tunneling splittings for the ground state $K_{a}$ $=0$ level and the excited state $K_{a}=1$ level. If we assume a value of $53 \mathrm{GHz}\left(\sim 1.8 \mathrm{~cm}^{-1}\right)$ for this splitting in the ground state $K_{a}$ $=0$ level, as estimated by Paul et al., ${ }^{22}$ we calculate the excited state splitting for the $K_{a}=1$ level to be $\sim 0.6 \mathrm{~cm}^{-1}$, or $19 \mathrm{GHz}$. This is similar to the value of $17 \mathrm{GHz}$ estimated by Paul et al. for the splitting in the ground state for $K_{a}=1$. For the $K_{a}=2$ $\leftarrow 1$ band, the $0.9 \mathrm{~cm}^{-1}$ separation between the $A_{1}^{+} / \mathrm{E}_{1}^{+} / \mathrm{B}_{1}^{+}$and $\mathrm{A}_{2}^{-} / \mathrm{E}_{2}^{-} / \mathrm{B}_{2}^{-}$tunneling levels provides the difference of the acceptor switching tunneling splittings for the ground state $K_{a}$ $=1$ level and the excited state $K_{a}=2$ level. If we again use the estimate of Paul et al. of $17 \mathrm{GHz}$ for the splitting in the ground state $K_{a}=1$ level, the splitting for the excited state $K_{a}=2$ level is calculated to be $1.5 \mathrm{~cm}^{-1}$, or $44 \mathrm{GHz}$. This is again similar to the value of $42 \mathrm{GHz}$ estimated by Paul et al. for the ground state $K_{a}=2$ level. These results indicate that excitation of the donor bend does not have a significant effect on the acceptor switching tunneling. This is unsurprising, considering that the bending motion of the hydrogen bond donor would be unlikely to affect the tunneling motion of the hydrogen bond acceptor. In contrast, excitation of the donor bend appears to have a significant effect on the interchange and bifurcation tunneling motions, as noted previously. 
It would be quite interesting to observe additional sub-bands of the donor bend, as well as to observe the acceptor bend, but these bands lie outside the current frequency range of our spectrometer. On the basis of our observations, the average of the $\mathrm{A}_{1}^{+} / \mathrm{E}_{1}^{+} / \mathrm{B}_{1}^{+}$and $\mathrm{A}_{2}^{-} / \mathrm{E}_{2}^{-} / \mathrm{B}_{2}^{-}$levels of the $K_{a}=0 \leftarrow 1$ band should lie at $\sim 1178.2 \mathrm{~cm}^{-1}$. The MULTIMODE calculations of Wang et al. ${ }^{26}$ predict that the acceptor band center lies at 1175 $\mathrm{cm}^{-1}$. The QCL used for this work can only go as low as $\sim 1182$ $\mathrm{cm}^{-1}$, but we have recently constructed an external cavity QCL (EC-QCL) system in collaboration with Gerard Wysocki at Princeton that can tune from $\sim 1135$ to $1220 \mathrm{~cm}^{-1}$. This new laser should make it possible to observe the additional subbands of the donor bend and the acceptor bend once it is completely integrated into our spectrometer. It would be especially interesting to observe the effect of excitation of the acceptor bend on the acceptor switching tunneling splittings.

\section{CONCLUSIONS}

We have reported the first rotationally resolved spectra of the bending mode of the hydrogen bond donor of water dimer. Two $\Delta K_{a}=+1$ bands were observed, and additional bands are almost certainly present, but outside the frequency coverage of our spectrometer. Both components of the acceptor switching tunneling doublet were observed for each band, which allowed us to estimate the acceptor switching tunneling splittings in the donor bend excited state on the basis of the previous estimates of the ground state splittings. We found that excitation of the donor bend has little effect on the acceptor switching tunneling. We have also determined the band center of the donor bend to be $1182.2 \mathrm{~cm}^{-1}$, which is in good agreement with previous theoretical predictions. Excitation of the donor bend does have a significant effect on the interchange tunneling, which made it difficult for us to obtain a detailed assignment of the individual tunneling components arising from this tunneling. The acceptor bend and additional bands of the donor bend should be easily observable using a light source with broader frequency tuning, which will allow additional insight into this fascinating molecular system.

\section{ASSOCIATED CONTENT}

\section{S Supporting Information}

List of the frequencies of the observed R-branch transitions for both the $K_{a}=1 \leftarrow 0$ and $K_{a}=2 \leftarrow 1$ bands. This material is available free of charge via the Internet at http://pubs.acs.org/.

\section{AUTHOR INFORMATION}

\section{Corresponding Authors}

*J. T. Stewart: e-mail, jacob.thomas.stewart@emory.edu.

*B. J. McCall: e-mail, bjmccall@illinois.edu.

\section{Present Address}

${ }^{\S}$ Department of Chemistry, Emory University, Atlanta, GA 30322, United States.

\section{Notes}

The authors declare no competing financial interest.

\section{ACKNOWLEDGMENTS}

The authors thank Professor Richard Saykally for suggesting the possibility of measuring the bending modes of $\left(D_{2} \mathrm{O}\right)_{2}$ using our QCL spectrometer. We also thank Professor Claire Gmachl for providing the QCLs used to perform the measurements reported here. Funding for this research was provided by a David and Lucile Packard Fellowship. J.T.S. has been supported by the Robert C. and Carolyn J. Springborn Fellowship from the University of Illinois.

\section{REFERENCES}

(1) Keutsch, F. N.; Saykally, R. J. Water Clusters: Untangling the Mysteries of the Liquid, One Molecule at a Time. Proc. Natl. Acad. Sci. U. S. A. 2001, 98, 10533-10540.

(2) Goldman, N.; Leforestier, C.; Saykally, R. J. A 'First Principles' Potential Energy Surface for Liquid Water from VRT Spectroscopy of Water Clusters. Philos. Trans. R. Soc. A 2005, 363, 493-508.

(3) Bukowski, R.; Szalewicz, K.; Groenenboom, G. C.; van der Avoird, A. Predictions of the Properties of Water from First Principles. Science 2007, 315, 1249-1252.

(4) Fraser, G. T. $\left(\mathrm{H}_{2} \mathrm{O}\right)_{2}$ : Spectroscopy, Structure and Dynamics. Int. Rev. Phys. Chem. 1991, 10, 189-206.

(5) Fellers, R. S.; Leforestier, C.; Braly, L. B.; Brown, M. G.; Saykally, R. J. Spectroscopic Determination of the Water Pair Potential. Science 1999, 284, 945-948.

(6) Dyke, T. R. Microwave Spectrum and Structure of Hydrogen Bonded Water Dimer. J. Chem. Phys. 1974, 60, 2929-2930.

(7) Dyke, T. R.; Mack, K. M.; Muenter, J. S. The Structure of Water Dimer from Molecular Beam Electric Resonance Spectroscopy. J. Chem. Phys. 1977, 66, 498-510.

(8) Odutola, J. A.; Dyke, T. R. Partially Deuterated Water Dimers: Microwave Spectra and Structure. J. Chem. Phys. 1980, 72, 5062-5070.

(9) Coudert, L. H.; Lovas, F. J.; Suenram, R. D.; Hougen, J. T. New Measurements of Microwave Transitions in the Water Dimer. J. Chem. Phys. 1987, 87, 6290-6299.

(10) Fraser, G. T.; Suenram, R. D.; Coudert, L. H. Microwave Electric-Resonance Optothermal Spectroscopy of $\left(\mathrm{H}_{2} \mathrm{O}\right)_{2}$. J. Chem. Phys. 1989, 90, 6077-6085.

(11) Suenram, R.; Fraser, G.; Lovas, F. Microwave Spectrum of $\left(\mathrm{D}_{2} \mathrm{O}\right)_{2}$. J. Mol. Spectrosc. 1989, 138, 440-449.

(12) Karyakin, E.; Fraser, G.; Suenram, R. Microwave Spectrum of the $K_{a}=1 \leftarrow 0$ Rotation-Tunnelling Band of $\left(\mathrm{D}_{2} \mathrm{O}\right)_{2}$. Mol. Phys. 1993, $78,1179-1189$.

(13) Fraser, G. T.; Lovas, F. J.; Suenram, R. D.; Karyakin, E. N.; Grushow, A.; Burns, W. A.; Leopold, K. R. Microwave and Submillimeter-wave Spectra of the Mixed Deuterated-Protonated Water-Dimer Isotopomers. J. Mol. Spectrosc. 1997, 181, 229-245.

(14) Zwart, E.; ter Meulen, J. J.; Meerts, W. L. The Submillimeter Rotation Tunneling Spectrum of $\left(\mathrm{D}_{2} \mathrm{O}\right)_{2}$. Chem. Phys. Lett. 1990, 173, $115-121$.

(15) Zwart, E.; ter Meulen, J.; Leo Meerts, W.; Coudert, L. The Submillimeter Rotation Tunneling Spectrum of the Water Dimer. J. Mol. Spectrosc. 1991, 147, 27-39.

(16) Busarow, K. L.; Cohen, R. C.; Blake, G. a.; Laughlin, K. B.; Lee, Y. T.; Saykally, R. J. Measurement of the Perpendicular RotationTunneling Spectrum of the Water Dimer by Tunable Far Infrared Laser Spectroscopy in a Planar Supersonic Jet. J. Chem. Phys. 1989, 90, 3937-3943.

(17) Pugliano, N.; Saykally, R. J. Measurement of the $\nu_{8}$ Intermolecular Vibration of $\left(\mathrm{D}_{2} \mathrm{O}\right)_{2}$ by Tunable Far Infrared Laser Spectroscopy. J. Chem. Phys. 1992, 96, 1832-1839.

(18) Braly, L. B.; Cruzan, J. D.; Liu, K.; Fellers, R. S.; Saykally, R. J. Terahertz Laser Spectroscopy of the Water Dimer Intermolecular Vibrations. I. $\left(\mathrm{D}_{2} \mathrm{O}\right)_{2}$. J. Chem. Phys. 2000, 112, 10293-10313.

(19) Braly, L. B.; Liu, K.; Brown, M. G.; Keutsch, F. N.; Fellers, R. S.; Saykally, R. J. Terahertz Laser Spectroscopy of the Water Dimer Intermolecular Vibrations. II. $\left(\mathrm{H}_{2} \mathrm{O}\right)_{2}$. J. Chem. Phys. 2000, 112, 10314-10326.

(20) Keutsch, F. N.; Braly, L. B.; Brown, M. G.; Harker, H. A.; Petersen, P. B.; Leforestier, C.; Saykally, R. J. Water Dimer Hydrogen Bond Stretch, Donor Torsion Overtone, and "In-Plane Bend" Vibrations. J. Chem. Phys. 2003, 119, 8927-8937.

(21) Huang, Z. S.; Miller, R. E. High-Resolution Near-Infrared Spectroscopy of Water Dimer. J. Chem. Phys. 1989, 91, 6613-6631.

(22) Paul, J. B.; Provencal, R. A.; Saykally, R. J. Characterization of the $\left(\mathrm{D}_{2} \mathrm{O}\right)_{2}$ Hydrogen-Bond-Acceptor Antisymmetric Stretch by IR 
Cavity Ringdown Laser Absorption Spectroscopy. J. Phys. Chem. A 1998, 102, 3279-3283.

(23) Groenenboom, G. C.; Wormer, P. E. S.; van der Avoird, A.; Mas, E. M.; Bukowski, R.; Szalewicz, K. Water Pair Potential of Near Spectroscopic Accuracy. II. Vibration-Rotation-Tunneling Levels of the Water Dimer. J. Chem. Phys. 2000, 113, 6702-6715.

(24) Keutsch, F.; Goldman, N.; Harker, H.; Leforestier, C.; Saykally, R. Complete Characterization of the Water Dimer Vibrational Ground State and Testing the VRT(ASP-W)III, SAPT-5st, and VRT(MCY-5f) Surfaces. Mol. Phys. 2003, 101, 3477-3492.

(25) Huang, X.; Braams, B. J.; Bowman, J. M.; Kelly, R. E. a.; Tennyson, J.; Groenenboom, G. C.; van der Avoird, A. New ab initio Potential Energy Surface and the Vibration-Rotation-Tunneling Levels of $\left(\mathrm{H}_{2} \mathrm{O}\right)_{2}$ and $\left(\mathrm{D}_{2} \mathrm{O}\right)_{2}$. J. Chem. Phys. 2008, 128, 034312.

(26) Wang, Y.; Carter, S.; Braams, B. J.; Bowman, J. M. MULTIMODE Quantum Calculations of Intramolecular Vibrational Energies of the Water Dimer and Trimer Using $a b$ initio-based Potential Energy Surfaces. J. Chem. Phys. 2008, 128, 071101.

(27) Shank, A.; Wang, Y.; Kaledin, A.; Braams, B. J.; Bowman, J. M. Accurate $a b$ initio and "Hybrid" Potential Energy Surfaces, Intramolecular Vibrational Energies, and Classical IR Spectrum of the Water Dimer. J. Chem. Phys. 2009, 130, 144314.

(28) Leforestier, C.; van Harrevelt, R.; van der Avoird, A. VibrationRotation-Tunneling Levels of the Water Dimer from an $a b$ initio Potential Surface with Flexible Monomers. J. Phys. Chem. A 2009, 113, 12285-12294.

(29) Leforestier, C.; Szalewicz, K.; van der Avoird, A. Spectra of Water Dimer from a New ab initio Potential with Flexible Monomers. J. Chem. Phys. 2012, 137, 014305.

(30) Paul, J. B.; Provencal, R. A.; Chapo, C.; Roth, K.; Casaes, R.; Saykally, R. J. Infrared Cavity Ringdown Spectroscopy of the Water Cluster Bending Vibrations. J. Phys. Chem. A 1999, 103, 2972-2974.

(31) Ayers, G.; Pullin, A. The I.R. Spectra of Matrix Isolated Water Species-I. Assignment of Bands to $\left(\mathrm{H}_{2} \mathrm{O}\right)_{2},\left(\mathrm{D}_{2} \mathrm{O}\right)_{2}$ and HDO Dimer Species in Argon Matrices. Spectrochim. Acta A 1976, 32, 1629-1639.

(32) Perchard, J. Anharmonicity and Hydrogen Bonding. III. Analysis of the Near Infrared Spectrum of Water Trapped in Argon Matrix. Chem. Phys. 2001, 273, 217-233.

(33) Engdahl, A.; Nelander, B. Water in Krypton Matrices. J. Mol. Struct. 1989, 193, 101-109.

(34) Coussan, S.; Roubin, P.; Perchard, J. Infrared Induced Isomerizations of Water Polymers Trapped in Nitrogen Matrix. Chem. Phys. 2006, 324, 527-540.

(35) Ceponkus, J.; Nelander, B. Water Dimer in Solid Neon. FarInfrared Spectrum. J. Phys. Chem. A 2004, 108, 6499-6502.

(36) Ceponkus, J.; Uvdal, P.; Nelander, B. Far-Infrared Band Strengths in the Water Dimer: Experiments and Calculations. J. Phys. Chem. A 2008, 112, 3921-3926.

(37) Brumfield, B. E.; Stewart, J. T.; Widicus Weaver, S. L.; Escarra, M. D.; Howard, S. S.; Gmachl, C. F.; McCall, B. J. A Quantum Cascade Laser cw Cavity Ringdown Spectrometer Coupled to a Supersonic Expansion Source. Rev. Sci. Instrum. 2010, 81, 063102.

(38) Brumfield, B. E.; Stewart, J. T.; McCall, B. J. High-Resolution Spectroscopy of the $\nu_{8}$ Band of Methylene Bromide Using a Quantum Cascade Laser. J. Mol. Spectrosc. 2011, 266, 57-62.

(39) Rothman, L. The HITRAN 2008 Molecular Spectroscopic Database. J. Quantum Spectrosc. Radiat. Transfer 2009, 110, 533-572.

(40) Stewart, J. T.; McCall, B. J. Additional Bands of the $\mathrm{Ar}-\mathrm{D}_{2} \mathrm{O}$ Intramolecular Bending Mode Observed Using a Quantum Cascade Laser. J. Mol. Spectrosc. 2012, 282, 34-38.

(41) Li, S.; Zheng, R.; Zhu, Y.; Duan, C. Rovibrational Spectra of the $\mathrm{Ar}-\mathrm{D}_{2} \mathrm{O}$ and $\mathrm{Kr}-\mathrm{D}_{2} \mathrm{O}$ van der Waals Complexes in the $\nu_{2}$ Bend Region of $\mathrm{D}_{2} \mathrm{O}$. J. Mol. Spectrosc. 2012, 272, 27-31.

(42) Dyke, T. R. Group Theoretical Classification of the TunnelingRotational Energy Levels of Water Dimer. J. Chem. Phys. 1977, 66, 492-497.

(43) Cruzan, J. D.; Braly, L. B.; Liu, K.; Brown, M. G.; Loeser, J. G.; Saykally, R. J. Quantifying Hydrogen Bond Cooperativity in Water: VRT Spectroscopy of the Water Tetramer. Science 1996, 271, 59-62.
(44) Herzberg, G. Infrared and Raman Spectra of Polyatomic Molecules; D. Van Nostrand: New York, 1945.

(45) Harker, H. A.; Keutsch, F. N.; Leforestier, C.; Scribano, Y.; Han, J.-X.; Saykally, R. J. Toward a Precise Determination of the Acceptor Switching Splitting in the Water Dimer. Mol. Phys. 2007, 105, 497512.

(46) Mills, I. M. Born-Oppenheimer Failure in the Separation of Low-Frequency Molecular Vibrations. J. Phys. Chem. 1984, 88, 532536.

(47) Ch'ng, L. C.; Samanta, A. K.; Czakó, G.; Bowman, J. M.; Reisler, $\mathrm{H}$. Experimental and Theoretical Investigations of Energy Transfer and Hydrogen-Bond Breaking in the Water Dimer. J. Am. Chem. Soc. 2012, 134, 15430-15435.

(48) Czakó, G.; Wang, Y.; Bowman, J. M. Communication: Quasiclassical Trajectory Calculations of Correlated Product-State Distributions for the Dissociation of $\left(\mathrm{H}_{2} \mathrm{O}\right)_{2}$ and $\left(\mathrm{D}_{2} \mathrm{O}\right)_{2}$. J. Chem. Phys. 2011, 135, 151102. 